\title{
Recombinant Human Anti-TGF-beta Monoclonal Antibody
}

National Cancer Institute

\section{Source}

National Cancer Institute. Recombinant Human Anti-T GF-beta Monoclonal Antibody. NCI Thesaurus. Code C84873.

A recombinant human IgG4 monoclonal antibody directed against transforming growth factor-beta (T GFb) with potential antineoplastic activity. Recombinant human anti-T GFbeta monoclonal antibody specifically targets and binds to all 3 isoforms of TGFb, thereby neutralizing TGFb isoforms 1, 2 and 3. This prevents activation of T GFbmediated signaling pathways. TGFb, a pleiotropic cytokine, is often overexpressed in a number of cancer cell types and is involved in cancer cell proliferation, differentiation, migration, invasion and angiogenesis. 